\title{
ethic@ \\ DEMOCRACIA E DIREITOS HUMANOS NO CONTEXTO DA REFORMULAÇÃO DA TEORIA DO DISCURSO
}

\author{
DEMOCRACY AND HUMAN RIGHTS IN THE CONTEXT OF \\ DISCOURSE THEORY'S REFORMULATION
}

\author{
LUÍS ALEXANDRE DIAS DO CARMO ${ }^{1}$ \\ (UVA/Brasil)
}

\begin{abstract}
RESUMO
Nessa pesquisa iremos tratar do projeto democrático de sociedade e os direitos humanos, no contexto da reformulação da teoria do discurso de Habermas em Direito e democracia $(D D)$ e no seu ensaio $O$ conceito de dignidade humana e a utopia realista dos direitos humanos $(D H)$ : as implicações da interpretação habermasiana da sua própria teoria dos direitos fundamentais (exposta em $D D$ ) à luz do conceito de dignidade humana (no ensaio $D H$ ). Conclusão: tal reformulação não é livre de problemas! Na fundamentação do direito enquanto tal, e especificamente dos direitos humanos, em $D D$, tal fundamentação não é posta de forma explícita e no outro texto, apresenta-se uma série de dificuldades, o que revela o caráter insatisfatório, do ponto de vista filosófico, de sua teoria do direito e dos direitos humanos.
\end{abstract}

Palavras-chave: Democracia; direitos humanos; dignidade humana; direito.

\begin{abstract}
The paper will deal with the democratic project of society and human rights in the context of the reformulation of Habermas' theory of discourse in Direito e Democracia (DD) and in his essay The concept of human dignity and the realistic utopia of human rights $(D H)$ : the implications of the habermasian interpretation of his own theory of fundamental rights (exposed in $D D$ ) by the light of the concept of human dignity in the essay $D H$. Conclusion: such a reformulation is not hassle-free! In the grounds of the law as such, and specifically of human rights, in $D D$, this reasoning is not explicitly stated and in the other text, there are a number of difficulties, which reveals the unsatisfactory, from the point of view philosophical view of his theory of law and human rights.
\end{abstract}

Keywords: democracy; human rights; human dignity; right.

\section{Introdução}

Neste artigo, iremos tratar do projeto democrático de sociedade e os direitos humanos, no contexto da reformulação da teoria do discurso de Habermas em $D D$ e no seu ensaio $D H$. Isso implica a questão da legitimação do direito enquanto tal, e especificamente dos direitos humanos. Com isso, queremos analisar a relação, que Habermas assume nessas duas obras com suas diferenças e especificidades de interpretação -, no que concerne ao tema dos direitos 
humanos e sua relação com a moral. Em que sentido é posta a fundamentação do direito enquanto tal, e em especial dos direitos humanos em $D D$ ? Quais as implicações da distinção elaborada, posteriormente, dos direitos humanos - em que salienta seu caráter peculiar de serem normas jurídicas que, contudo, se apresentam como normas morais - no que concerne à fundamentação de um sistema de direitos, e de modo específico dos direitos humanos?; quais as implicações da interpretação que Habermas elabora da sua própria teoria dos direitos fundamentais (exposta em $D D$ ) à luz do conceito de dignidade humana (exposta em $D H)$ ?

Para o tratamento desse conjunto de questões, vamos organizar nosso texto, partindo, primeiramente, da análise da fundamentação do direito em $D D$ de 1992. Para isso, começaremos com a caraterização das propriedades do direito moderno e, junto com a reformulação da leitura kantiana do direito, trataremos da validade do direito, sua validade através do processo legislativo e a caracterização do direito como medium da tensão entre facticidade e validade: sua aceitabilidade racional e positividade. Importante nesse contexto é a explicitação da relação de complementaridade entre direito positivo e moral racional, bem como, a investigação sobre a mediação entre direitos humanos e soberania popular. No segundo momento, iremos tratar da relação da moral via dignidade humana com os direitos humanos, no ensaio $D H$ de 2011. E por fim, nas considerações finais equivalendo a um terceiro momento, um balanço do conjunto de questões acima levantadas.

\section{Fundamentação do direito em Direito e Democracia.}

Habermas publicou o livro $D D$ em 1992, no qual apresenta os elementos basilares de uma teoria discursiva do direito na perspectiva de uma racionalidade procedimental. Explicar essa teoria discursiva do direito significa responder à pergunta pela legitimação do direito. Vejamos, no que segue, a especificidade dessa teoria discursiva do direito, ou o modo de sua fundamentação.

\section{Forma do Direito Moderno}

Com as qualidades formais do direito - positividade, legalidade e formalismo Habermas concebe o direito moderno como possibilitador da liberdade em termos negativos, pois aqui é permitido, logo, é lícito tudo aquilo que não é proibido. Como isso é possível?

Segundo Habermas, o conceito do direito subjetivo, que estabelece os limites no interior dos quais um sujeito está justificado a empregar livremente a sua vontade, tem um papel central 
na moderna compreensão do direito. Desde Locke, Rosseau e Kant, o direito privado - que se apoia na liberdade de contratos e na propriedade - vale como paradigma para o direito em geral.

Para Habermas, o importante nesse caso é o conceito de legalidade de Kant, no qual objetiva tratar da validade do direito, tomando como ponto de partida os direitos subjetivos. Para ele, Kant apresenta a validade do direito como uma relação de duplo aspecto, a saber, entre coerção e liberdade. Acrescenta que essa relação expressa a tensa relação entre facticidade e validade. Portanto, o vínculo entre facticidade e validade é estabilizado na validade jurídica (HABERMAS, 1997, T. I, p. 48).

A partir da leitura habermasiana do duplo aspecto da validade do direito, apresentado por Kant, e em sintonia com a sua teoria da ação (de Habermas), o direito positivo determina sua validade por "um modo de ver empírico" dos atores e, de forma tautológica, pela sua adequação a procedimentos juridicamente válidos e, dessa forma, suas normas são reconhecidas como direito, com caráter vinculante (HABERMAS, 1997, T. I, p. 50). A validade do direito, conforme Habermas, nos remete a uma referência simultânea: a sua validade social e ao seu caráter de legitimidade. A validade social das normas jurídicas é determinada pela sua possível aceitação fática, adesão fática às suas prescrições. Aqui o direito se apoia não sobre a facticidade de formas de vida consuetudinárias e tradicionais, e sim sobre uma facticidade artificial fruto da garantia que o direito possui de ameaça de sanção do monopólio da força pelo estado, e é essa força aglutinante que garante o cimento da coesão social. O segundo aspecto, diz respeito ao caráter de legitimidade das normas jurídicas que se define pelo resgate discursivo de sua pretensão de validade normativa; importante aqui é o fato de elas terem surgido num processo legislativo racional - portanto, elas poderiam ter sido justificadas sob pontos de vista pragmáticos, éticos e morais (HABERMAS, 1997, T. I, p. 50). Assim, Habermas afirma que a legitimidade de uma regra independe do fato de ela conseguir impor-se, portanto, sua validade independe de um consenso factual com base na força dos costumes e dos hábitos seculares. Para ele, é o contrário disso, pois é a suposição de legitimidade do ordenamento jurídico que garante tanto a validade social quanto a obediência fática aos seus preceitos, senão o direito ficaria à mercê do puro arbítrio (MOREIRA, 2007, p 122; HABERMAS, 1997, T. I, p. 50).

A partir da validade do direito - validade fática e sua legitimidade -, Habermas afirma que o direito permite aos membros da comunidade jurídica um relacionamento ou enfoque duplo no que concerne à norma jurídica: enfoque objetivador e performativo. ${ }^{2}$ No primeiro caso, o ator se orienta pelo sucesso próprio, e assim a "norma jurídica vem a ser um obstáculo fático para a obtenção de seu sucesso ou êxito, uma vez que a consequente sanção advinda de sua transgressão faz com que à ação ilícita se siga uma consequência jurídica" ( MOREIRA, 2007, p 
122). Neste caso, o ator atribui à norma jurídica, o status de um fato com consequências prognosticáveis. Já, o enfoque performativo refere-se aos atores que agem na busca do entendimento comunicativamente gestado e a norma amarra sua vontade livre através de uma pretensão de validade deontológica.

Segundo a perspectiva assumida pelo ator, a norma jurídica, para quem age em termos estratégicos, se encontra num nível que limita externamente o seu espaço de opções; ao passo que, para o que age comunicativamente, a norma jurídica "se situa no nível de expectativas obrigatórias de comportamento, em relação às quais supõe um acordo racionalmente motivado entre parceiros jurídicos" (HABERMAS, 1997, T. I, p. 51-2) dessa forma, a norma jurídica se apresenta como garantidora objetiva da liberdade. Neste caso, também, o ator atribui à norma jurídica, o status de um fato com obrigatoriedade deontológica de uma expectativa normativa de comportamento (HABERMAS, 1997, T. I, p. 52). Com isso, compreende-se que a validade jurídica de uma norma expressa a garantia da legalidade do comportamento em geral, no sentido de uma obediência à norma, bem como, a legitimidade da própria regra que torna possível a obediência à norma por respeito à lei (HABERMAS, 1997, T. I, p. 52)

Habermas acrescenta que essa análise do modo de validade do direito, - que supõe suas regras serem seguidas pelo receio anunciado de sua transgressão, e, ao mesmo tempo, se erguerem com uma pretensão a uma validade normativa, que requer dos destinatários seu seguimento por respeito à lei ou por dever -, exige no plano da normatização do direito a exigência racional de legitimação pós-metafísica. Enfim, ela revela que o direito positivo tem que legitimar-se (HABERMAS, 1997, T. I, p. 52), e essa exigência racional de legitimação ocorre no processo legislativo como espaço da integração social.

Habermas considera que o direito não se restringe em garantir apenas a configuração da liberdade subjetiva; pois o reconhecimento recíproco dos direitos de cada um por todos os outros baseia-se, no mais, em leis legítimas que garantam a cada um liberdades iguais, de modo que a liberdade do arbítrio de cada um possa manter-se junto com a liberdade de todos. (HABERMAS, 1997, T. I, p. 50)ํ․ Ele considera que a moral, por si, cumpre essa função. Já, no que se refere as regras do direito positivo, essa função deve ser preenchida pelo legislador político. Assim, no sistema jurídico, o processo legislativo se põe como o âmbito da integração social (HABERMAS, 1997, T. I, p. 52).

Com isso, no processo legislativo as pessoas abandonam o papel de sujeitos privados do direito, da perspectiva solipsista e assumem, através do papel de cidadãos, a figura de membros de uma comunidade jurídico-política livremente associada. Nessa comunidade jurídica, um acordo sobre os princípios normativos que irão regular a convivência, pode ser conseguido de 
dois modos: primeiramente, através da tradição ou dos costumes; segundo, por meio de um entendimento com base em regras reconhecidas normativamente.

Assim, com a característica da relação entre coerção e validade da legitimidade, exigese para tal um processo de legislação no qual os cidadãos devem poder participar na condição de sujeitos do direito que agem orientados não apenas pelo sucesso, (HABERMAS, 1997, T. I, p. 53) mas, por uma participação orientada ao entendimento.

Para que o processo de legislação seja eficiente do ponto de vista da legitimação, é necessário que lhe seja constitutivo os direitos de comunicação e de participação política e, dessa forma, "os direitos subjetivos não podem ser tidos como os de sujeitos jurídicos privados e isolados: eles têm que ser apreendidos no enfoque de participantes orientados pelo entendimento, que se encontram numa prática intersubjetiva de entendimento" (HABERMAS, 1997, T. I, p. 53). Dessa forma, o conceito do direito moderno absorve a atividade do pensamento democrático, conforme estabelecido por Kant e Rousseau, no sentido de que a pretensão de legitimidade de uma ordem jurídica construída com direitos subjetivos só pode ser resgatada através da força socialmente integradora da "vontade unida e coincidente de todos" os cidadãos livres e iguais (HABERMAS, 1997, T. I, p. 53).

A autonomia jurídica dos cidadãos nos chama a atenção para a circunstância de que a coerção fática deve comprovar sua legitimidade como leis da liberdade "a partir de um processo legislativo em que, pela correição procedimental, constitui-se enquanto norma que efetiva a liberdade" (MOREIRA, 2007, p 125). Habermas frisa que, neste caso, se reproduz, no processo de positivação do direito, a tensão entre facticidade e validade - de modo diferenciado da validade de normas legais - visto ser permitido descrever o comportamento legal a partir da esfera de conformidade às normas jurídicas que entraram em vigor, seja em virtude da ameaça de sanção, seja em virtude do cumprimento de uma norma que se supõe válida pelas decisões de um processo legislativo. A especificidade da facticidade no processo legislativo ocorre, "na medida em que a permissão para a coerção jurídica é deduzida de uma expectativa de legitimidade associada à resolução do legislador (a qual poderia ser diferente e corrigível em princípio)" (HABERMAS, 1997, T. I, p. 53-4). A positividade do direito vem acompanhada da expectativa de que o processo democrático da legislação, portanto da correição processual, legitima a suposição de racionalidade e validade das normas estatuídas. Na positividade do direito não temos a manifestação da facticidade de um poder arbitrário ou autoritário da vontade, ao invés, trata-se da manifestação de uma vontade legítima que emana do povo, e neste sentido, resulta de uma "autolegislação presumivelmente racional de cidadãos politicamente autônomos". 
Neste caso, as liberdades subjetivas de ação são complementadas por direitos subjetivos especificados por meio de direitos dos cidadãos que buscam sua autonomia, e não apenas a liberdade de arbítrio. O direito, afirma Habermas, só poderá conservar sua força integradora, se:

\begin{abstract}
... a totalidade dos destinatários singulares das normas jurídicas puder considerar-se autora racional dessas normas. Nesta medida, o direito moderno nutre-se de uma solidariedade concentrada no papel do cidadão que surge, em última instância, do agir comunicativo. A liberdade comunicativa dos cidadãos pode, como vimos, assumir, na prática da autodeterminação organizada, uma forma mediada através de instituições e processos jurídicos, porém não pode ser substituída inteiramente por um direito coercitivo (HABERMAS, 1997, T. I, p. 54).
\end{abstract}

Como vimos, o processo de validade do direito se legitima através do processo legislativo. Porém, este autonomamente não basta como fonte de legitimidade do direito, pois os membros de uma comunidade jurídica específica têm de se atribuir direito, para que possam ser considerados membros de uma comunidade jurídica autônoma. $\mathrm{O}$ ordenamento jurídico se constitui, ao mesmo tempo, como criação e reflexo da produção discursiva da opinião e da vontade dos membros de uma dada comunidade jurídica. Portanto, o processo legislativo compreende-se como aquela instância que se constitui fruto da relação entre direitos que cada cidadão tem de se atribuir e direitos ligados à sua autonomia política. Dessa forma, se legitima o direito de modo a estabilizar a tensão manifesta entre autonomia privada e autonomia pública no procedimento legislativo. O surgimento da legitimidade a partir da legalidade não é paradoxal, pois a visão da compreensão discursiva do sistema dos direitos conduz o olhar, para o lado, em que " a carga da legitimação dos cidadãos desloca-se para os procedimentos da formação discursiva da opinião e da vontade, institucionalizados juridicamente; de outro lado, a juridificação da liberdade comunicativa significa também que o direito é levado a explorar fontes de legitimação das quais ele não pode dispor” ( HABERMAS, 1997, T. I, p. 168).

Nesse quadro, se põe a pergunta: como é possível fundamentar a legitimidade de regras que podem ser modificadas pelo legislador político? Tratando dessa questão na tradição do direito natural, se poderia dizer que se recorrendo a esse direito natural de fundamentação religiosa ou metafísica, o turbilhão da temporalidade da facticidade das normas, para o qual o direito é atraído, podiam ser contidas pela moral. Assim, "o direito positivo temporalizado devia - no sentido de uma hierarquia de leis - permanecer subordinado ao direito moral de validade eterna e receber deste as suas orientações permanentes" (HABERMAS, 2015, vol. IV, p. 125). Portanto, a normatividade no âmbito jurídico era fruto de uma medida de correspondência entre o direito positivo e uma moral superior. A legitimidade do direito se expressava na aproximação a esse direito racional moral e, dessa forma, se apresenta a secular associação do direito com a 
moral. Por fim, o direito moderno especificado em suas propriedades formais, não se satisfaz com a intervenção por parte de uma moral imediatamente informativa para a ação.

\section{Sobre a relação de complementaridade entre direito positivo e moral racional}

Os direitos subjetivos dos ordenamentos modernos têm o sentido de desvincular as pessoas jurídicas dos mandamentos morais. Nesse caso, não é possível estabelecer a relação de subordinação entre direito positivo e o direito moral, pois os direitos subjetivos, como visto, concedem aos atores margens de manobra para as ações orientadas estrategicamente ao sucesso. O direito moderno, segundo Hobbes, afirma o princípio de que é permitido tudo o que não é explicitamente proibido. Diferentes são as especificidades da moral: nesta há uma simetria entre direitos e deveres, enquanto os deveres jurídicos começam por definir-se, como uma consequência de permissões, da legitimação da configuração da limitação jurídica das liberdades subjetivas. Habermas afirma que o privilégio do tratamento dos direitos frente aos deveres, já é próprio aos conceitos fundamentais, e explica-se com base nos conceitos modernos de pessoa jurídica e de comunidade jurídica (HABERMAS, 2015, vol. IV, p. 126).

Nessa linha de determinação da relação entre o direito e a moral, estabelece-se um vínculo em que a complementaridade entre ambas as esferas prevalece sobre a subordinação: a moral que não é limitada no espaço e tempo, abrange todas as pessoas naturais na complexidade das suas histórias de vida e visa à proteção da integridade de pessoas singulares plenamente individuadas; contrariamente a esta caracterização, uma comunidade jurídica, que está sempre localizada no espaço e no tempo, “... protege a integridade dos que lhe pertencem na exata medida em que estes assumem o estatuto artificialmente produzido de titulares de direitos subjetivos". (HABERMAS, 2015, vol. IV, p. 126).

Essa complementaridade também diz respeito ao âmbito da extensão. Nesse campo, as matérias que necessitam de regulação jurídica são, simultaneamente, mais restritas e mais amplas que a questões moralmente importantes: seriam mais restritas em virtude de que apenas um comportamento exterior (juridicamente vinculativo), é acessível à regulação jurídica, e mais amplas, porque "o direito - como meio de organização do poder político - não se refere apenas à regulação de conflitos de ação interpessoal, mas igualmente a prossecução de objetivos e programas políticos" ( HABERMAS, 2015, vol. IV, p. 126). Esse é o motivo para se afirmar que as questões jurídicas não dizem respeito unicamente a questões morais, mas igualmente se referem a questões pragmáticas, éticas, bem como, à elaboração de compromissos entre interesses divergentes. Diferentemente da pretensão de validade normativa de recorte preciso 
dos mandamentos morais, a pretensão de legitimidade das normas jurídicas caracteriza-se por motivos diversos, pois a “... a prática da justificação legislativa depende de uma rede extensa de discursos e negociações - e não unicamente de discursos morais" (HABERMAS, 2015, vol. IV, p. 126; HABERMAS, 1997, T. I, p. 141).

Com isso, Habermas considera que por meio dos elementos de legitimidade da validade jurídica, é possível estabelecer uma relação do direito com a moral. Tal relação não deve ser de subordinar o direito à moral, no sentido de uma hierarquia de direitos de diferente dignidade. Essa posição leva ao engano, tal qual procedeu a concepção jusnaturalista. Habermas pretende estar além tanto das teorias religiosas ou metafísicas do direito natural como do positivismo jurídico, e neste sentido a moral racional e o direito positivo encontram-se numa relação de complementação recíproca. Portanto, o direito pode ser compreendido como complemento funcional da moral. Habermas considera que direito e moral referem-se aos mesmos problemas, porém sob ângulos distintos, todavia, a moral e o direito distinguem-se, em virtude, da moral racional representar uma forma de saber cultural, enquanto o direito adquire obrigatoriedade também a nível institucional (HABERMAS, 1997, T. I, p. 141). Ele considera que o direito positivo pode dispensar as pessoas que julgam e agem moralmente das exigências cognitivas, motivacionais e organizacionais da moral. No entanto, tal concepção "não exime o legislador e a justiça da preocupação de que o direito permaneça em sintonia com a moral. Mas as regulações jurídicas são demasiado concretas para poderem legitimar-se unicamente por não contradizerem os princípios morais" (HABERMAS, 2015, vol. IV p. 127). Diante disso, Habermas, põe a pergunta: "mas onde, senão a um direito moral de ordem superior, pode o direito positivo ir então buscar a sua legitimidade?" (HABERMAS, 2015, vol. IV p. 127).

Com base na concepção de que o direito complementa co-originariamente a moral, Habermas, afirma que não podemos interpretar os direitos fundamentais como simples cópias de direitos morais, devido ao fato de que normas de ação gerais se ramificam em regras morais e jurídicas. A autonomia moral e autonomia política são co-originários, pois o princípio do discurso tem um conteúdo normativo, porém se encontra num nível de abstração, o qual, apesar do seu conteúdo moral, é neutro em relação ao direito e à moral, pois refere-se a normas de ação em geral.

Esse parcimonioso princípio do discurso, de conteúdo normativo que afirma o sentido da imparcialidade de juízos práticos e que se refere a normas de ação em geral, é o fundamento dos discursos práticos da moral, da ética e do direito enquanto saberes normativos do agir humano. Estes tipos de argumentos ou discursos resulta da diferenciação da lógica do questionamento e, assim, dos tipos de razões e dos tipos de discurso. Estas regras de 
argumentação operacionalizam o princípio do discurso e são respostas a problemas pragmáticos, ético e morais.

O princípio moral que trata de normas de ação, que só podem ser justificadas sob o ponto de vista da consideração simétrica dos interesses, resulta de uma especificação do princípio do discurso. Da mesma forma, o princípio democrático que significa "que somente podem pretender validade legítima as leis jurídicas capazes de encontrar o assentimento de todos os parceiros do direito, num processo jurídico de normatização discursiva”, (HABERMAS, 1997, T. I, p. 145) - este princípio também explica "o sentido performativo da prática de autodeterminação de membros do direito que se reconhecem mutuamente como membros iguais e livres de uma associação estabelecida livremente" (HABERMAS, 1997, T. I, p. 145) -, resulta também de uma especificação do princípio do discurso. Dessa forma, o princípio da democracia não se encontra no mesmo nível do princípio da moral, o que constitui um ponto de vista da diferenciação entre a forma jurídica e a moral. ${ }^{4}$

Nesse contexto, Habermas vai levantar a questão dos direitos humanos e sua mediação com a democracia. O direito vai ter que comprovar a sua legitimidade no que concerne a salvaguarda da liberdade, pois ele terá o papel de proteger igualmente a autonomia dos seus concernidos enquanto intervenientes e afetados. A positividade do direito obriga a uma peculiar cisão da autonomia, diferentemente da autonomia moral que na tradição kantiana compreendese de forma unitária, pois imputa a cada indivíduo in própria persona a obediência a normas que ele estabelece para si próprio de acordo com o seu próprio juízo imparcial (HABERMAS, 2015, vol. IV p. 127). As normas jurídicas expressam sua vinculatividade, não somente através de processos de formação da opinião e do juízo, mas remonta, também, às decisões coletivamente vinculativas de instâncias de criação e aplicação do direito (HABERMAS, 2015, vol. IV p. 127). Dessa forma, se apresenta uma partilha de papéis entre aqueles que criam e dizem o direito, e aqueles, os destinatários que se encontram submetidos ao direito respectivamente vigente. Assim, Habermas conclui que no âmbito moral, surge uma autonomia monolítica e, na esfera do direito, se apresenta uma autonomia, apenas na forma dupla da autonomia privada e autonomia pública.

Habermas propõe que estas formas de autonomia sejam conciliadas e não prejudique uma a outra, já que indica que as liberdades de ação subjetivas do sujeito do direito privado e a autonomia pública dos cidadãos do Estado desempenham papéis distintos, irredutíveis, porém, complementares. Isso se baseia na ideia de que só considera as pessoas jurídicas como autônomas na medida em que, no exercício dos seus direitos como cidadãos do Estado, se 
entendem como autores precisamente dos mesmos direitos a que devem obediência enquanto destinatários (HABERMAS, 2015, vol. IV p. 128).

\section{Sobre a mediação entre direitos humanos e soberania popular e os modelos normativos de democracia.}

As teorias do direito jusracionalistas trataram da questão da legitimidade diferenciadamente, remetendo, por um lado, para o princípio da soberania popular, ou, por outro lado, fazendo referência ao primado das leis enquanto garantido pelos direitos humanos. Então, nessa perspectiva, o princípio da soberania popular exprime-se nos direitos comunicativos e participativos - que asseguram a autonomia pública dos cidadãos do Estado - e o primado das leis se manifesta por meio dos direitos fundamentais clássicos - garantidores da autonomia privada dos cidadãos da sociedade. Diante desse quadro, a legitimidade do direito se define quando se apresenta como meio destinado a garantir igualmente a autonomia privada e a autonomia pública.

$\mathrm{Na}$ filosofia política, ambos os princípios são tratados de forma concorrente, não conseguindo equilibrar a tensão entre soberania popular e direitos humanos, pois a ênfase recai ora, por um lado, na autonomia política dos cidadãos que "deve consubstanciar-se na autoorganização de uma comunidade que dá as suas leis a si própria por intermédio da vontade soberana do povo"; ora, por outro lado, se enfatiza a autonomia privada dos cidadãos que "deve tomar forma nos direitos fundamentais que garantem o primado anônimo das leis" (HABERMAS, 2015, vol. IV p. 128). No contexto desse debate entre o republicanismo - que sempre priorizou a autonomia pública dos cidadãos do Estado frente as liberdades pré-políticas dos sujeitos privados e afirmara que os direitos humanos baseavam sua legitimidade ao resultado do auto-entendimento ético e da autodeterminação soberana de uma comunidade política, - e o liberalismo - que denunciou o perigo da tirania desta ou daquela maioria, bem como, postulara a primazia dos direitos humanos e afirmara que os direitos humanos “constituíam por inerência limites legítimos que impediam a vontade soberana do povo de usurpar esferas invioláveis da liberdade subjetiva" (HABERMAS, 2015, vol. IV p. 128) - : pretende Habermas, fazer jus à intuição, presente em Rosseau e Kant, mas não convertida em conceito, de pensar a plausibilidade da co-originariedade dessas duas coisas. Habermas considera que eles não conseguiram entender que "a ideia dos direitos humanos, que se formula no direito a liberdades de ação subjetivas iguais, não deve ser nem meramente imposta ao 
legislador soberano como limite externo, nem instrumentalizada para os fins deste último como requisito funcional" (HABERMAS, 2015, vol. IV p. 128).

Para mostrar essa relação de reciprocidade, recorre-se ao processo democrático que confere ao processo legislativo a sua força geradora de legitimidade. Esse processo democrático, presente nos discursos e negociações, se legitima com base no princípio do discurso que estipula que podem licitamente reivindicar legitimidade precisamente aquelas regulações, a que todos os potencialmente afetados poderiam assentir enquanto participantes em discursos racionais. Aqui é o lugar onde se pode formar a vontade política racional e, é importante acrescentar, que "essa presunção de racionalidade que deve estar na base do processo democrático acabará por ter de se apoiar numa modalidade comunicativa artificiosa: o que importa são as condições em que as formas de comunicação necessárias a uma criação legítima do direito podem ser, por seu lado, juridicamente institucionalizadas" (HABERMAS, 2015, vol. IV p. 128). A possibilidade do nexo entre os dois princípios se define na medida em que:

o requisito da institucionalização jurídica de uma prática do uso público das liberdades comunicativas por parte dos cidadãos do Estado ser preenchido precisamente pelos direitos humanos. Os direitos humanos que possibilitam o exercício da soberania popular não podem ser impostos a essa prática como uma limitação proveniente do exterior (HABERMAS, 2015, vol. IV p. 129-130).

No entanto, segundo Habermas, o outro verso da moeda não pode desaparecer, pois a análise até agora feita se converte de plausibilidade para os direitos comunicativos e participativos que asseguram o exercício da autonomia política, mas não no que concerne aos direitos humanos que são garantia da autonomia privada dos cidadãos. Neste sentido, ele considera que devemos converter plausível não apenas o reconhecimento do direito à maior medida possível de liberdades subjetivas de ações iguais, mas também, e, em termos iguais, de direitos fundamentais que constituem a cidadania, bem como, uma abrangente proteção jurídica do indivíduo. Segundo Habermas, tais direitos que asseguram a cada qual, de forma geral, a condução dos interesses de vida privados "em condições de igualdade de oportunidades, revestem-se de um valor intrínseco, não se dissolvem, em todo o caso, no seu valor instrumental para a formação democrática da vontade" (HABERMAS, 2015, vol. IV p. 130). Para esclarecer o nexo entre autonomia privada e pública, é necessário precisar a tese de que os direitos humanos possibilitam a prática da autodeterminação dos cidadãos da forma exposta que se segue.

Sobre a relação co-originária (HABERMAS, 2015, vol. IV p. 125) entre direitos humanos e soberania popular, Habermas, afirma a possibilidade dos direitos humanos se legitimarem em 
termos morais, no entanto, diz que não é lícito dispô-lo de modo paternalista, qual carapuça, a um soberano. Partindo do princípio de que a autonomia jurídica dos cidadãos exige que os destinatários do direito possam, simultaneamente, compreenderem-se como seus autores, Habermas, considera incongruente a compreensão do legislador democrático que pretendesse dispor dos direitos humanos como algo semelhante a deveres morais e limitasse a positivá-los. Habermas chama atenção para o fato de que os cidadãos, enquanto co-legisladores das normas jurídicas, só podem intervir de forma autônoma no processo legislativo pela linguagem ou medium do direito e enquanto sujeitos de direito. A conclusão é a consideração de que a concepção democrática da autonomia tem de dotar-se -sem liberdade de escolha - de validade no medium do direito (HABERMAS, 2015, vol. IV p. 131). Neste sentido, Habermas conclui sua reflexão do nexo entre os dois princípios, com a seguinte consideração:

\begin{abstract}
Mas se as pressuposições comunicativas com base nas quais os cidadãos avaliam, à luz do princípio do discurso, se o direito que resulta do seu processo criador é um direito legítimo, houverem de ser, por seu lado, institucionalizadas - sob a forma de direitos políticos dos cidadãos -, o código jurídico tem de estar disponível enquanto tal. Mas para a instituição desse código jurídico é necessário gerar o estatuto das pessoas jurídicas que, enquanto titulares de direitos subjectivos, integram uma associação voluntária de companheiros jurídicos e, se for necessário, reivindicam em juízo de forma efectiva os seus direitos. Não existe nenhum direito sem a autonomia privada de todo aquele que é pessoa jurídica. Assim sendo, sem os direitos fundamentais, que asseguram a autonomia privada dos cidadãos, também não existiria nenhum medium para a institucionalização jurídica daquelas condições de que os cidadãos, no seu papel de cidadãos do Estado, pudessem fazer uso da sua autonomia pública (HABERMAS, 2015, vol. IV p. 131).
\end{abstract}

Eis, portanto, a explicação que Habermas desenvolve para mostrar a pressuposição mutua entre autonomia privada e autonomia pública, sem que nenhum possa reivindicar um primado sobre o outro: os direitos subjetivos devem ser considerados como condições necessárias - possibilitam - para o exercício da soberania popular, o que implica que também esses direitos têm que ser fundamentados na base da autonomia democrática.

Com essa exposição, podemos dizer que a democracia deliberativa procedimental enquanto modelo normativo da política contemporânea, pretende mediar e superar os limites da concepção liberal de democracia, com proteção dos direitos individuais, e da perspectiva republicana, com ênfase nos direitos de participação política. Isso é possível pela concepção da política como deliberação, um processo de autocompreensão dos cidadãos enquanto participantes em comunidades linguísticas e dialógicas. Portanto, de uma situação universal em que os cidadãos, no gozo de sua autonomia pessoal, se reconhecem e condicionam reciprocamente mediante a autolegislação e, nessa pressuposição dessa situação, também, gozam de autonomia política. 
Habermas em seu modelo procedimental de democracia parte da constatação de um déficit democrático da atividade política e das formas institucionais das democracias hodiernas, na medida que incluem a concepção do “... afastamento progressivo da ideia normativa fundamental de que todo governo legítimo deve incorporar a "vontade do povo", e que o sentido dos processos de democratização apontam para o nexo entre arranjos institucionais e uma legislação racional, para a participação política e, principalmente, para as deliberações públicas entre os cidadãos". (VITALE; MELO; 2008, p. 224).

Entende-se, neste modelo deliberativo, que para tornar possível a legitimação racional da aceitação das regras do jogo democrático, devemos nos basear no ideal normativo da soberania popular em que essas mesmas regras são fruto da vontade do povo, portanto, tais regras precisam estar conectadas com a prática de autodeterminação pública entre cidadãos considerados livres e iguais. Assim, o exercício do poder político só pode ser justificado com base no "uso público da razão" ou nas práticas de argumentação pública livre entre os cidadãos.

No modelo democrático deliberativo os cidadãos participam do processo de deliberação pública com o intuito de elucidar e formar sua opinião e vontade em função de uma tomada de decisão supostamente mais racional. A questão consiste, então, em saber como formar uma vontade política, como é possível uma formação política da vontade sob condições do pluralismo. Passa-se a fonte da legitimidade democrática do modelo da "vontade geral”, comum a todos, para uma deliberação comum a todos. (MANIN, 1987, p. 351-2). O fundamento racional da aceitação de uma ordem política apresenta-se não simplesmente ao momento em que os cidadãos tomam uma decisão, “....mas se concentra no processo precedente de formação da opinião e da vontade por meio do qual uma certa decisão pôde ser racionalmente examinada em relação a argumentos e razões oferecidos por todos os participante em discursos racionais." (VITALE; MELO; 2008, p. 228). Para Habermas, esse modelo de democracia deliberativa implica, também, “... uma ênfase nos procedimentos e condições para que decisões coletivamente obrigatórias sejam não apenas legítimas por serem coletivas, mas que o sejam também por terem sido examinadas e aceitas racionalmente. (VITALE; MELO; 2008, p. 228229).

Com esse intuito, Habermas em sua teoria do discurso reconstrói o processo de deliberação pública, na medida que clarifica as condições simétricas de participação na deliberação pública para que o processo político seja reconstruído como um processo intersubjetivo de formação racional da vontade. Em seguida, Habermas mostra que essas condições de aceitabilidade racional e legitimidade ocorrem numa solução procedimental para os conflitos substantivos tematizados na deliberação. Com isso teríamos que desenvolver a 
questão que envolve a teoria do discurso e o núcleo procedimental da deliberação, no entanto considerando que essas considerações gerais sejam suficientes para os objetivos do trabalho, passemos para outro ponto. ${ }^{5}$

Feitas estas considerações, gostaria, por fim, de fazer um balanço com posicionamentos críticos sobre a análise da teoria da fundamentação do direito e de modo específico dos "direitos humanos", elaborados por Habermas, em Direito e democracia.

Um dos posicionamentos críticos elaborado pela filosofia contemporânea do direito, (OLIVEIRA, 2010; LAMORE, 1993; MAUS, 1995, p. 507-562.; PINZANI, 2000) diz respeito ao caráter circular em que se põe o procedimento argumentativo habermasiano. Considera-se que estamos diante de um argumento circular pelo seguinte raciocínio: como vimos, foi posto que "os direitos fundamentais constituem tanto as condições lógicas como históricas para a realização do discurso democrático. Que só esse discurso possa, contudo, garantir a efetivação desses direitos é um argumento para a democracia, mas produz um círculo prático, isto é, a vinculação nas democracias existentes entre direitos da liberdade e direitos de participação...”; então, o posicionamento conclusivo é que isso não demonstra a co-originariedade entre esses direitos, nem do ponto de vista lógico nem histórico (OLIVEIRA, 2010, p. 271).

Outra questão pertinente que esses autores abordaram, se refere ao entendimento de que Habermas, em suas considerações reflexivas sobre a fundamentação do direito, recai numa postura que mistura dois níveis discursivos: o histórico e o sistemático. O objetivo explícito de Habermas "é fazer uma análise da função que o direito exerce nas sociedades contemporâneas, ou seja, seu papel de mecanismo fundamental de integração social; no entanto, é possível mostrar que sua estratégia argumentativa pressupõe elementos normativos” (OLIVEIRA, 2010). Como vimos em nossa análise de $D D$, a passagem entre esses níveis discursivos muitas vezes são postos, sem que seja chamada a atenção especial das especificidades diferenciais de tais níveis discursivos, por exemplo, em que sentido é possível uma fundamentação dos princípios normativos do discurso, que se entendem enquanto condição da análise crítica dos fatos empíricos, serem apropriados por uma reconstrução empírica? (CARMO, 2011. APEL, 2004).

\section{Sobre o ensaio $O$ conceito de dignidade humana e a utopia realista dos direitos humanos}

Aqui Habermas tem como tarefa a análise do vínculo do conceito de direitos humanos com o conceito de dignidade humana. Ele considera que a institucionalização dos direitos humanos ocorre a partir da violação das experiências da dignidade humana. O texto termina por alcançar o nível de uma reflexão teórica sobre o fundamento moral dos próprios direitos humanos. Como isso é possível? 
Habermas objetiva chegar ao diagnóstico de que a dignidade humana desempenha um papel proeminente nos discursos dos direitos humanos e na jurisprudência (HABERMAS, 2012, p. 8). Ele constata a circunstância interessante de que somente após a Segunda Grande Guerra Mundial o conceito filosófico de dignidade humana tenha sido introduzido nos textos do direito e nas diferentes constituições nacionais então vigentes, não obstante ser tematizado desde a antiguidade e adquirido no pensamento kantiano sua validade atual. Habermas também afirma que o conceito de dignidade humana como conceito jurídico não está presente nem na declaração clássica dos direitos humanos do século XVIII, nem nas codificações do século XIX. Diante desse quadro, ele levanta a pergunta: por que no direito o discurso dos direitos humanos surgiu anteriormente ou bem mais cedo ao discurso do conceito da dignidade humana?

Visando apresentar sua tese, Habermas considera haver uma assimetria histórica entre a história dos direitos humanos referente ao século XVII e o surgimento recente do conceito de dignidade humana nas codificações do direito das gentes e decisões jurídicas do último século (HABERMAS, 2012, p. 8). Habermas, após exemplificar, faz a pergunta se é somente no contexto histórico do holocausto que a ideia de direitos humanos é depois carregada moralmente com o conceito de dignidade humana? (HABERMAS, 2012, p. 8). Põe-se a dúvida em virtude de que logo em seguida ele lança a tese de que:

Em contraposição à suposição de que foi atribuída retrospectivamente uma carga moral ao conceito de direitos humanos por meio do conceito de dignidade humana, pretendo defender a tese de que, desde o início, mesmo que ainda primeiro de modo implícito, havia um vínculo conceitual entre ambos os conceitos. Direitos humanos sempre surgiram primeiro a partir da oposição à arbitrariedade, opressão e humilhação (HABERMAS, 2012, p. 11).

Habermas pretende mostrar que o surgimento dos direitos humanos se alimenta da indignação dos humilhados pela violação da dignidade humana e que esse vínculo se apresentou desde sempre (HABERMAS, 2012, p. 11). Ele pretende defender a tese de que a dignidade humana é a fonte moral da qual os direitos fundamentais extraem seu conteúdo, ou a concepção de que a inviolabilidade da dignidade do ser humano é a fonte de todo direito fundamental. Diante disso, não considera a dignidade humana no sentido de uma expressão vazia para um catálogo de direitos humanos individuais (HABERMAS, 2012, p. 11). Com a defesa dessa tese, Habermas considera possível mostrar e explicar, - contra a rejeição total dos direitos humanos e as tendências das teorias atuais que pretendem atenuar seu conteúdo radical -, a força política explosiva de uma utopia concreta, portanto, de uma utopia realista dos direitos humanos. Vejamos, no que segue, as razões teóricas jurídicas que Habermas sustenta para sua tese. 
Ele considera que os direitos humanos são menos controversos que os conceitos jurídicos universais. No entanto, constata que operadores do direito chegam a resultados distintos no que concerne a aplicação desses direitos em diferentes situações históricas, pois a caracterização da universalidade abstrata dos direitos humanos, requer que sejam concretizados em cada caso particular. Habermas afirma que devido as dificuldades de interpretação, eles são mais apropriados para a função de compromissos negociáveis, por exemplo, no caso da fundação das Nações Unidas, especificamente no trato de direito das gentes e nas negociações de pactos sobre os direitos humanos, "o apelo ao conceito de dignidade humana sem dúvida facilitou a produção de um consenso sobreposto entre partes de diferentes origens culturais" (HABERMAS, 2012, p. 12). Habermas afirma que esse papel de "compromisso, que a dignidade humana desempenhou no decurso da diferenciação e da difusão dos direitos humanos, e ocasionalmente também na neutralização de diferenças intransponíveis", não basta para explicar a assimetria temporal entre a história dos direitos humanos e o surgimento recente do conceito de dignidade humana nas codificações do direito das gentes, ou não consegue explicar a origem tardia da dignidade humana como conceito jurídico (HABERMAS, 2012, p. 12). Nesse contexto, Habermas reafirma sua tese fundamental da justificação da substância normativa da dignidade humana igual de cada um implícito no surgimento dos direitos humanos (HABERMAS, 2012, p. 11).

Habermas apresenta uma função heurística da dignidade humana, pois a experiência de violação da dignidade humana tem uma função de descoberta, como é o caso, diante dos desafios históricos, por exemplo, das condições sociais de vida insustentáveis e da marginalização das classes sociais pauperizadas, da discriminação de estrangeiros, etc. Assim, ele conclui que à luz dos desafios históricos, em cada momento são atualizadas outras dimensões do sentido da dignidade humana. Este vínculo entre a dimensão moral da dignidade humana e os direitos fundamentais são apresentados na afirmação seguinte de Habermas:

Essas características da dignidade humana, especificadas em cada ocasião, podem levar tanto a uma maior exploração do conteúdo normativo dos direitos fundamentais assegurados, como ao descobrimento e à construção de novos direitos fundamentais. Com isso a intuição implícita no pano de fundo penetra de início a consciência dos atingidos e depois os textos do direito, para então ser conceitualmente articulada (HABERMAS, 2012, p. 11).

Diante disso, dando sequência ao seu raciocínio, Habermas certifica a relação "forte" entre o conceito de dignidade humana e o conceito do direito, pois fala da necessidade de justificar a criação de novos direitos fundamentais e uma expansão (maior exploração) do conteúdo moral normativo dos direitos fundamentais das características da dignidade humana. 
O desdobramento dessa relação se faz de maneira abreviada, por exemplo, na constituição da República de Weimar de 1919 quando reivindica direitos sociais e trata em seu artigo 151 da "garantia de uma existência humana digna para todos" - fazendo um uso abreviado da retórica da dignidade humana na medida que o conceito de dignidade humana se esconde no uso predicativo de uma palavra usada no sentido cotidiano. Já em 1944 a Organização Internacional do Trabalho (OIT) faz um uso da retórica da dignidade humana de forma explícita e posteriormente na Declaração Universal dos Direitos Humanos, no artigo 22, quando já faz a exigência de direitos econômicos, sociais e culturais, de modo que as pessoas possam viver sob condições que são "indispensáveis para a sua dignidade e ao livre desenvolvimento de sua personalidade" (HABERMAS, 2012, p. 15). Caracterizados os direitos que marcam estes diferentes períodos, é possível falarmos de diferentes momentos ou "gerações" de direitos humanos. Diante disso, Habermas afirma que a experiência da violação da dignidade humana é caracterizadora por revelar também o vínculo lógico das quatro categorias de direitos humanos, pois estes apenas podem resgatar a promessa moral do respeito pela dignidade humana de cada um, na condição de estarem numa interação igual em todas as suas categorias:

A partir da função heurística da dignidade humana, revela-se também o vínculo lógico das quatro categorias de direitos conhecidas: os direitos fundamentais apenas podem resgatar politicamente a promessa moral de respeitar a dignidade humana de cada um se eles interagirem igualmente em todas as suas categorias (HABERMAS, 2012, p. 15).

Então, temos os direitos fundamentais clássicos que se expressam nos direitos liberais de liberdade ou direitos negativos que servem para impedir a interferência do Estado na esfera privada e os direitos de participação democrática, os quais só adquirem validade igual para todos os cidadãos quando não forem excluídos dos direitos sociais e culturais. Diante dessa situação cabe a pergunta: o que possibilita o equilíbrio entre essas diversas modalidades de direitos fundamentais? Em termos de exclusão, Habermas afirma: a política implementada nos últimos anos no mundo que pretende assegurar uma vida autônoma aos cidadãos, primariamente por meio de garantias do livre exercício da atividade econômica, não torna possível esse equilíbrio entre as diversas categorias de direitos fundamentais. Então, ele levanta a tese de que "a dignidade humana, que é uma e a mesma em todo lugar e para cada um, fundamenta a indivisibilidade dos direitos fundamentais" (HABERMAS, 2012, p. 16).

O desenvolvimento dessa relação entre direitos humanos e o conceito de dignidade humana explica também a importância desse último na jurisprudência. Habermas afirma que "quanto mais fortemente os direitos fundamentais penetram o todo do sistema jurídico, mais 
frequentemente estendem sua influência para além das relações verticais dos cidadãos individuais com o Estado, permeando as relações horizontais entre os cidadãos individuais" (HABERMAS, 2012, p. 16). Com isso surge o problema importante ligado aos direitos humanos que diz respeito a colisões entres eles e também um aumento dessas colisões que exigem entre situações de reivindicações de direitos fundamentais concorrentes uma ponderação na aplicação desses direitos. Dessa forma finaliza Habermas, "em tais casos difíceis, muitas vezes só é possível fundamentar uma decisão quando se recorre a uma violação da dignidade humana válida de modo absoluto e que reivindica um primado" (HABERMAS, 2012, p. 16). Diríamos, nesse caso, que nessa relação entre a promessa moral da dignidade humana e o direito humano se expressa a validade absoluta do primeiro frente à forma jurídica, e isso nos remete à associação à clássica relação metafísica entre moral e direito. No entanto, não é esse o objetivo de Habermas! Nesse caso, prossigamos no percurso que ele desenvolve. Nessa concepção integrada dos direitos humanos, ele afirma que:

a dignidade humana é um sismógrafo que mostra o que é constitutivo para uma ordem jurídica democrática - a saber, precisamente os direitos que os cidadãos de uma comunidade política devem se dar para poderem se respeitar reciprocamente como membros de uma associação voluntária de livres e iguais. Somente a garantia desses direitos humanos cria o status de cidadãos que, como sujeitos de direitos iguais, pretendem ser respeitados em sua dignidade humana (HABERMAS, 2012, p. 17).

Após dois séculos de história constitucional moderna, fica claro o que marcou o desenvolvimento dessa relação desde seu início: para Habermas "a dignidade humana forma algo como o portal por meio do qual o conteúdo igualitário-universalista da moral é importado ao direito" (HABERMAS, 2012, p. 17). Assim, ele concebe o conceito de dignidade humana como uma dobradiça conceitual que liga a moral simetricamente válida para todos com o direito e com a legislação democrática e assim, na sua cooperação sob circunstâncias históricas favoráveis, foi possível emergir uma ordem política fundamentada nos direitos humanos (HABERMAS, 2012, p. 17-8). Apresenta-se assim uma relação dos conceitos expressos, na seguinte ordem: moral, dignidade humana (mediador) e direitos humanos.

As clássicas declarações dos direitos humanos fundamentadas em direitos naturais ou sagrados e inalienáveis expressam ou revelam ainda suas origens com base em doutrinas metafísicas e religiosas. No entanto, Habermas considera que:

num Estado neutro do ponto de vista das concepções de mundo, tais predicados têm o papel de um guardador de lugar; relembram-nos do modo cognitivo - para além do controle do Estado - de uma fundamentação do conteúdo moral transcendente desses direitos, capaz de ser aceita universalmente (HABERMAS, 2012, p. 18). 
Acrescente-se que para os pais fundadores desses direitos humanos, eles estavam cientes de que os direitos humanos, independentemente de sua justificação ao campo da moral, teriam de ser "esclarecidos" democraticamente, especificados e implementados no âmbito da esfera de uma comunidade política (HABERMAS, 2012, p. 18). Diante disso, a promessa moral deve ser resgatada na moeda jurídica. Isso nos leva a pergunta: como é possível tal mediação com a necessidade de manter a autonomia de ambas as esferas? Segundo Habermas, ao fato dos direitos humanos terem uma face dupla, como a face de Jano, um lado voltado para a moral e o outro voltado ao direito. Ele afirma que os direitos humanos possuem a forma do direito positivo que asseguram aos indivíduos um espaço de liberdade, e que isso é possível independente do conteúdo moral exclusivo desses mesmos direitos humanos.

\footnotetext{
Independentemente de seu conteúdo moral exclusivo, eles possuem a forma de direitos subjetivos positivos coercitivos que asseguram aos indivíduos um espaço de liberdade e pretensões. Estão dispostos de modo que são concretizados pela via da legislação democrática, especificados caso a caso por meio da jurisprudência e impostos com sanções estatais (HABERMAS, 2012, p. 18).
}

A conclusão de Habermas é a afirmação de que os direitos humanos envolvem de modo específico a parte de uma moral racional e "que 'pode ser traduzida no medium do direito coercitivo e ter realidade política efetiva na robusta configuração de direitos fundamentais efetivos" (HABERMAS, 2012, p. 18- 9).

Feita esta exposição, Habermas, nesse momento, põe uma nota para esclarecer sua posição aqui exposta em comparação com a reflexão sobre o sistema de direitos feita em Faktizität und Geltung, cap. III e também em Der demokratischen Rechtsstaat - eine paradoxe Verbindung widersprüchlicher Prinzipien? (HABERMAS, 2012, p. 154-75). Ele considera que a abordagem feita aqui nesse texto acerca da relação entre direito e moral é coerente com sua postura apresentada nos textos anteriormente citados - em que o direito seria expressão da tensão entre facticidade e validade; com isso, Habermas acredita que não seria necessário da sua parte uma revisão de sua "introdução originária do sistema de direitos" (HABERMAS, 2012, p. 19, nota 19).

Após fazer essa observação, ele apresenta uma diferenciação acerca do conceito de direito humano e moral, e que tal distinção conceitual se mostraria como elemento corroborador da necessidade de justificar a falta de revisão de sua apresentação "originária do sistema de direitos", exposto em Faktizität und Geltung. Poderíamos especular que a indicação de tal diferenciação, mostraria que o direito ainda seria expressão da tensão entre facticidade e validade e que, portanto, não caberia uma leitura que legitimaria o direito como subordinado à 
moral, como fez o jusnaturalismo racional? Nesse caso, as coisas parecem que não estão livres de problemas, como afirma Habermas. Mas, prossigamos, e eis sinteticamente a apresentação de Habermas:

\begin{abstract}
Os direitos humanos diferenciam-se dos direitos morais entre outras coisas por estarem orientados para uma institucionalização - portanto, devem ser criados - e para isso necessitam de uma formação da vontade comum democrática, enquanto pessoas agindo moralmente consideram, sem mediações adicionais, um ao outro como sujeitos que de saída estão imersas em uma rede de deveres e direitos morais" (HABERMAS, 2012, p. 19).
\end{abstract}

Dando sequência à sua escrita da nota 19, Habermas ressalta que naquele tempo, porém, não levou em conta duas coisas:

\begin{abstract}
Primeiro, as experiências cumulativas de dignidade violada formam uma fonte de motivação moral para a práxis constitucional, sem precedentes históricos, no final do século XVIII; segundo, a noção geradora de status do reconhecimento social da dignidade do outro fornece a ponte conceitual entre o conteúdo moral do respeito igual de cada um e a forma jurídica dos direitos humanos (HABERMAS, 2012, p. 19).
\end{abstract}

Bem, vimos que essas "duas coisas" tratam da temática que envolve a relação entre moral, dignidade humana e direitos humanos que estamos abordando, e nesse caso cabe a pergunta: seriam então elas, elementos indicadores da necessidade de revisão de sua introdução originária do sistema de direitos apresentados em Faktizität und Geltung? A resposta de Habermas se manteria no que foi exposto anteriormente: a não necessidade dessa revisão do seu sistema de direitos. Porém, para nós, essas considerações parecem não implicar na mesma conclusão de Habermas. Percebemos, então, não haver uma posição clara de Habermas que não nos leve ao impasse, acerca dessa questão. No mais, ele apenas acrescenta na mesma nota 19, que "deixarei de lado aqui se esse deslocamento do foco para essas questões tem consequências adicionais para minha interpretação deflacionada do princípio do discurso " $\mathrm{D}$ " na fundamentação dos direitos fundamentais" (HABERMAS, 2012, p. 19, nota 19). Nesse caso, o próprio Habermas nos remete à sua discussão a partir das objeções de Karl-Otto Apel em Habermas, Zur Architektonik der Diskursdifferenzierung. Kleine Replik auf eine grosse Auseinandersetzung. A título de esclarecimento, acrescentamos apenas que tal artigo se mantém na linha da "sua introdução originária do sistema de direitos" apresentados em Faktizität und Geltung. Nesse caso, parece que não temos uma saída para o impasse anteriormente constatado.

Bem, com a finalização da avaliação que Habermas apresentou na nota 19, voltemos ao texto principal que diz respeito ao conceito de dignidade humana e a utopia realista dos direitos humanos e, assim, examinaremos o papel catalizador desempenhado pelo conceito de dignidade na composição dos direitos humanos a partir da moral e da forma do direito. 
$\mathrm{Na}$ categoria dos direitos humanos voltaram a ser relacionados "dois elementos que, no decurso inicial dos tempos modernos, se liberaram da simbiose do direito natural entre fatos e normas, autonomizando-se e desenvolvendo-se, a princípio, em direções opostas" (HABERMAS, 2012, p. 19). Nessa combinação encontra-se, de um lado, a esfera da moral interiorizada, ancorada na consciência subjetiva e fundamentada racionalmente; do outro lado, o direito coercitivo positivo a serviço da administração estatal e no papel de meio de organização para o controle do intercâmbio capitalista de mercadorias. Dessa forma, "o conceito de direitos humanos decorre de uma improvável síntese desses dois elementos. E esse vínculo realizou-se por meio da dobradiça conceitual da dignidade humana (HABERMAS, 2012, p. 20). Habermas mostra que o conceito de dignidade humana sofreu, nesse processo de vinculação, uma transformação. Considerando a genealogia dos direitos humanos, ele pretende mostrar "o papel da dignidade humana na mudança de perspectiva que vai dos deveres morais aos direitos jurídicos" (HABERMAS, 2012, p. 20).

A diferença entre moral racional e direito racional é muitas vezes obscurecida, em virtude das teorias modernas apoiarem-se num fundamento comum que diz respeito à autonomia do indivíduo e no princípio do respeito igual por cada um. No entanto, Habermas trabalha a diferença conceitual e a relação entre ambas as esferas: "a moral nos impõe deveres que perpassam completamente todas as esferas de ação, o direito moderno cria espaços livres ao arbítrio privado e à configuração da vida individual” (HABERMAS, 2012, p. 21). No direito é "permitido tudo o que não está explicitamente proibido, os direitos subjetivos, e não os deveres, formam o ponto de partida da constituição do sistema de direitos" (HABERMAS, 2012, p. 21). e assim, para os modernos, o modelo do direito é a autorização igual para todas as pessoas fazerem ou deixarem de fazer o que lhes agrada no espaço da lei. Com o intuito de tratar de explicitar a diferenciação entre estes conceitos, Habermas, afirma que os atores lidam ou tem perspectivas diferentes, no momento em que seguem mandamentos morais e quando do exercício dos seus direitos.

Em uma relação moral, uma pessoa se pergunta o que ela deve a outra pessoa, independentemente de sua relação social com ela - o quão estranha essa outra pessoa é, como se comporta e o que se espera dela. Em contrapartida, pessoas que estão numa relação jurídica umas com as outras reagem às pretensões que o respectivo outro ergue em relação a ela. Em uma comunidade jurídica, as obrigações surgem para a primeira pessoa em virtude das pretensões que uma segunda pessoa pode lhe apresentar (HABERMAS, 2012, p. 21).

Então, após a caracterização da diferença e relação complementar entre mora racional e direito, podemos concluir: essa explanação desenvolvida por Habermas é parte de um conjunto 
de questões cujo objetivo principal é mostrar o impulso moral dos direitos humanos a partir da proteção da dignidade humana igual de cada um e que essa relação explica a força explosiva de uma utopia concreta. Habermas afirma que somente assim, desse "vínculo entre dignidade humana e direitos humanos produz aquela força explosiva da moral no medium do direito, no interior do qual deve ser efetuada a construção das ordens políticas justas" (HABERMAS, 2012, p. 37). Por extrapolar nossos objetivos, não vamos analisar as reflexões que Habermas desenvolve para esta última consideração. ${ }^{6}$

\section{Conclusão}

Feita essa reflexão da proposta de fundamentação do direito enquanto tal, e especificamente dos "direitos humanos" em $D D$ de 1992 e do papel da moral via dignidade humana na fundamentação dos direitos humanos no texto $D H$ de 2011 , tentemos agora caracterizar as diferenças e especificidades de posicionamento, que Habermas assume nessas duas obras, no que concerne ao tema dos direitos humanos e sua relação com a moral. Como vimos, a análise que desenvolvemos perante os dois textos sobre a fundamentação do direito e especificamente dos direitos humanos, nos leva a uma série de outras questões que procuramos esclarecer no conjunto da nossa pesquisa, a saber: em que sentido é posta a fundamentação do direito enquanto tal, e especificamente dos direitos humanos, por Habermas, em $D D$ ? Quais as implicações da distinção elaborada, posteriormente, dos direitos humanos - em que salienta seu caráter peculiar de serem normas jurídicas que, contudo, se apresentam como normas morais no que concerne à fundamentação do sistema de direitos, e especificamente dos direitos humanos?; quais as implicações da "suposta releitura" que Habermas elabora da sua própria teoria dos direitos fundamentais (exposta em $D D$ ) à luz do conceito de dignidade humana? Portanto, como se estabelece, nestas diferentes perspectivas, a relação entre moral e direitos humanos? Procuremos, então, chegar a uma posição conclusiva para o conjunto dessas questões, no que segue.

Como vimos, Habermas, no ensaio sobre $D H$ explicita, entre outras questões, uma reflexão teórica sobre o fundamento moral, via o conceito de dignidade humana, dos próprios direitos humanos. Ele defendeu a tese de que o conceito de direitos humanos é carregado moralmente com o conceito de dignidade humana, pois nos direitos humanos se expressaria a "substância normativa" da dignidade humana igual de cada um. O apelo aos direitos humanos alimenta-se da indignação dos humilhados pela violação de sua dignidade humana. Assim, os direitos humanos são respostas a tais violações e pretendem restabelecer e garantir a igual dignidade a cada indivíduo. 
Neste contexto, cabe remetermos à posição que o próprio Habermas assumiu em obras precedentes no que concerne ao tema dos direitos humanos. Por exemplo, em $D D$, eles não são tematizados diretamente, pois ele não fala propriamente de direitos humanos, mas de direitos fundamentais que são as condições formais para a institucionalização jurídica daquela forma de formação de opinião e vontade em que a soberania do povo encontra sua configuração jurídica, portanto, direitos fundamentais que os membros de uma comunidade jurídica e política se garantem reciprocamente e que em virtude disso não são princípios do direito que valem independentemente de sua positivação. Em alguns ensaios posteriores a $D D$ escrito por Habermas (HABERMAS, 2002, p. 185-227; HABERMAS, 2015, vol. IV, p. 227-74), ele se serve do conceito de direitos humanos, mas salienta seu caráter peculiar de serem normas jurídicas que, contudo, se apresentam como normas morais (PINZANI, 2012, p. XI-XXXI e PINZANI, 2000). Os direitos humanos têm um duplo caráter, como uma cabeça de Jano, com uma face voltada para o direito positivo e outra para a moral: "enquanto normas de constituição, expressos na forma de normas gerais, eles têm uma validade positiva, mas enquanto direitos que dizem respeito a cada pessoa enquanto ser humano, eles possuem uma validade pré-positiva universal, semelhante à universalidade das normas morais" (OLIVEIRA, 2010, p. 272).

Segundo M. Oliveira, essa concepção dupla dos direitos humanos não é compreendida no sentido da tradição jusnaturalista, já que para Habermas o conceito de direito humano não tem origem moral e sim jurídica. Mais, tudo isso implica alguns problemas, na versão habermasiana da fundamentação do direito em geral e especificamente dos direitos humanos, que M. Oliveira sintetiza:

\footnotetext{
por se tratar de direitos universais, eles se referem necessariamente a uma ordem jurídica universal, que teria todos os seres humanos como destinatários. Esses direitos humanos, contudo, enquanto direitos fundamentais, são direitos positivos e, enquanto tais, podem ser mudados ou postos fora de validade, o que dificilmente se pode compreender, já que antes se tratava para ele de direitos pré-positivos, referentes ao ser humano enquanto tal. Precisamente por poderem ser postos em questão e transformados é que Habermas não introduz um catálogo definitivo de direitos, mas apenas um modelo de direitos. Os direitos humanos, em última instância, são para ele direitos que os parceiros de uma ordem jurídica têm que conceder uns aos outros, quando pretendem regrar legitimamente sua vida coletiva (OLIVEIRA, 2010, p. 272).
}

Nesse caso, a questão da fundamentação do direito enquanto tal e de modo específico a fundamentação dos direitos humanos não é posta explicitamente, o que apresenta certas dificuldades na exposição habermasiana e revela o caráter insatisfatório de sua teoria do direito e dos direitos humanos. Tais dificuldades são mais explícitas principalmente no ensaio recente 
de Habermas sobre o aspecto moral dos direitos humanos, em $D H$. Vejamos, algumas dessas dificuldades.

Como vimos, ele considera que a dignidade humana é expressão ou a "fonte" moral da qual os direitos fundamentais extraem seu conteúdo. Vimos que o objetivo de Habermas foi, com essa explicação, mostrar a força política explosiva de uma utopia concreta, opondo-se a Carl Schmitt que rejeitara os direitos humanos, bem como, se opõe a outras tentativas de atenuar o seu conteúdo radical ou substituí-lo por um deflacionamento brando dos direitos humanos, ao separar os direitos humanos de seu impulso moral que é a proteção da dignidade igual de cada um. Então, é através dessa relação interna entre a dignidade humana e os direitos humanos que se produz a utopia realista dos direitos humanos ou "aquela fusão explosiva da moral no medium do direito, no interior do qual deve ser efetuada a construção das ordens políticas justas" (HABERMAS, 2012, p. 11). Diante desse quadro, A. Pinzani interpreta Habermas, aqui no ensaio $D H$, da seguinte forma: "é como se Habermas relesse sua própria teoria dos direitos fundamentais (exposta em Direito e democracia) à luz do conceito de dignidade: nessa perspectiva, o que os cidadãos querem é justamente ser respeitados em sua dignidade" (PINZANI, 2012, p. XIII-XIV).

Vimos que o próprio Habermas afirmou na nota 19 do seu ensaio, que não acreditava que sua reflexão iria exigir uma revisão em sua introdução ao sistema de direitos apresentado em Faktizität und Geltung. Porém, acreditamos junto com A. Pinzani que tal releitura apresenta uma série de problemas, a saber, em primeiro lugar, ela

coloca um elemento de fundamentação moral no centro daquela que, na obra de 1992 era uma reconstrução discursiva da gênese dos direitos, na qual contava somente a perspectiva jurídico-política da criação de uma comunidade de jurisconsortes (Rechtsgenossen) capazes de atribuir-se reciprocamente iguais direitos, sem que houvesse uma motivação estritamente moral por trás desse reconhecimento recíproco (PINZANI, 2012, p. XIII-XIV).

Segunda questão a ser considerada, é que nesta última obra Habermas considera os direitos fundamentais como uma concretização dos direitos humanos ancorada na constituição de um país. Dessa forma eles (os direitos humanos) formam "uma utopia realista na medida em que não mais projetam a imagem decalcada da utopia social de uma felicidade coletiva; antes eles ancoram o próprio objetivo ideal de uma sociedade justa nas instituições de um Estado constitucional” (PINZANI, 2012, p. XIII-XIV). Um divisor de águas nessa releitura se apresenta aqui, quando "Habermas chega a falar de uma "ideia transcendente de justiça", assumindo, de maneira aparente, aquela posição decididamente normativa própria das teorias da justiça que sempre quis expressamente evitar" (PINZANI, 2012, p. XIII-XIV). Como vimos, 
Habermas, com a pretensão de alegar motivos ao problema posto na sua nota 19 , remete para a diferenciação entre direitos humanos e direitos morais, bem como, a constatação da não observância primeiro, que "as experiências cumulativas de dignidade violada formam um fonte de motivação moral para a práxis constitucional, sem precedentes históricos, no final do século XVIII; segundo, "a noção geradora de status do reconhecimento social da dignidade do outro fornece a ponte conceitual entre o conteúdo moral do respeito igual de cada um e a forma jurídica dos direitos humanos" (HABERMAS, 2012, p. 19). Tais alegações me parecem ser insuficientes como resposta, ao conjunto de dificuldades que traz a releitura habermasiana da teoria dos direitos fundamentais apresentados em $D D$.

Outra questão a ser apresentada, é percebermos que não estamos perante a tensão entre facticidade e validade que perpassa como fio condutor sua obra de 1992 e que considera importante redefinir ou reafirmar a validade das pretensões de justiça elaboradas nos discursos jurídicos e políticos; e agora, de realizar concretamente, na realidade jurídica, "um ideal normativo que o próprio Habermas define como "transcendente" - termo que parece remeter a um ideal definido de uma vez por todas, mais do que a um baseado em pretensões de validade revisáveis" (PINZANI, 2012, p. XV). No caso da aceitação dessa interpretação também adviria que o direito deixaria de ser considerado meramente "como instrumento que permite preencher as lacunas criadas pela perda de uma eticidade compartilhada e consegue assim assumir o papel desempenhado anteriormente pela moral (como no livro de 1992); deixaria, em suma, de ser apenas construído de maneira meramente análoga à moral racional e receberia antes uma "carga moral" (PINZANI, 2012, p. XV).

O resultado disso é que, diferentemente da obra de 1992, o direito é o responsável por eliminar a tensão entre ideia e realidade dos direitos humanos, bem como, pretender levar à realização a dignidade de cada um (PINZANI, 2012, p. XV). Então, haveria, nesse caso, uma aproximação entre direito e moral bem mais forte do que em $D D$.

O caminho que percorremos relativo à compreensão da fundamentação do direito enquanto tal, e especificamente dos direitos humanos, no qual Habermas elabora uma suposta releitura da sua própria teoria dos direitos fundamentais, não é livre de problemas. Em $D D$ tal fundamentação não é posta de forma explícita e, no ensaio de 2011, traz uma série de dificuldades, o que nos revela o caráter insatisfatório do ponto de vista filosófico de sua teoria do direito e dos direitos humanos. 


\section{Notas}

${ }^{1}$ Prof. do Mestrado Acadêmico em Filosofia da Universidade Estadual Vale do Acaraú-UVA na área de "Filosofia Prática", Sobral, (CE), Brasil. E-mail: alexdiasdocarmo@yahoo.com.br

${ }^{2}$ Esse duplo enfoque corresponde ao duplo aspecto de validade do conceito kantiano de legalidade identificada a coerção e a liberdade. MOREIRA, 2007, p 122.

${ }^{3}$ Assim o direito não se restringe a configuração da liberdade subjetiva em termos negativos, pois o corpo político se constitui de pessoas que se reconhecem mutuamente enquanto portadoras de direitos recíprocos. $\mathrm{O}$ sujeito de direito se constitui enquanto paradigma para o corpo político, uma vez que a sociedade reconhece em cada um de seus membros a capacidade pessoal e inalienável de ter direitos e obrigações (MOREIRA, 2007, p. 123-4).

${ }^{4} \mathrm{O}$ importante, no caso, é que essa estratégia argumentativa tem a vantagem de evitar duas posições inadequadas e de conservar, para além delas, a exigência de uma fundamentação normativa do direito: "a redução da validade jurídica à validade moral, como defende o jusnaturalismo, ou a total independência do direito frente à moral, como quer o positivismo" (OLIVEIRA, M. 2010, p. 269-70).

${ }^{5}$ Para uma visão ampla da democracia deliberativa, tratar Seyla Benhabib, "Toward a deliberative modelo of democratic legitimacy", in Seyla Benhabib (Ed.), Democracy and difference: contesting the boundaries of the political, Princeton University Press, 1996. Outra obra de referência para este debate: J. Bohman, W. Regh (Eds.), Deliberative democracy: essas on reason and politics, Cambridge: MIT Press, 1997.

${ }^{6}$ Conferir, nesse caso, a unidade três (3) do artigo DH. HABERMAS, 2012. 


\section{Referências bibliográficas}

APEL, K.-Otto. Com Habermas, contra Habermas: Direito, Discurso e Democracia. Org. Moreira, L, (org.); São Paulo: Ed. Landy, 2004.

ARAÚJO, L. B. Leite. Moral, Direito e Política. Sobre a Teoria do Discurso de Habermas, In: Oliveira, M.; Aguiar, O.; Andrade e Silva Sahd, L.F.N. de (orgs.). Filosofia Politica Contemporânea. Petrópolis: Vozes, 2003.

BENHABIB, S. Toward a deliberative modelo of democratic legitimacy, in Seyla Benhabib (Ed.), Democracy and difference: contesting the boundaries of the political, Princeton University Press, 1996.

BOHMAN, J.; REGH, W. (Eds.), Deliberative democracy: essays on reason and politics, Cambridge: MIT Press, 1997.

CARMO, L. A. D. Discurso Filosófico e a Arquitetônica da ética do discurso. Apel versus Habermas. Fortaleza, Ed. EdUECE, 2011.

DUTRA, D. J. Volpato. Razão e consenso em Habermas. A teoria discursiva da verdade, da moral, do direito e da biotecnologia. Florianópolis: Ed.UFSC. 2005.

HABERMAS, Jürgen. Direito e Democracia. R. de Janeiro: T. Brasileiro, 1997. Tradução de Flávio Siebeneichler.

. "Paradigms of Law", in: ROSENFELD, m. e ARATO, A. (eds.). Habermas on law and Democracy - Critical Exchange. Berkley: University of California Press, 1998.

. A ideia kantiana de paz perpétua - à distância histórica de 200 anos, in: A inclusão do outro. São Paulo: Loyola, 2002. Tradução de George Sperber e Paulo Soethe.

O conceito de dignidade humana e a utopia realista dos direitos humanos, in: Sobre a constituição da Europa, São Paulo: Ed. Unesp, 2012, Tradução de Werle, D., Repa, L., Melo, R. S.

. Sobre o nexo interno entre o Estado de direito e a democracia, in: Teoria Política. Obras Escolhidas, Lisboa: edições 70, 2015, vol. IV, p. 125. Tradução: Lumir Nahodil.

- O Estado de direito democrático - uma associação paradoxal de princípios contraditórios?, in: Teoria Política. Obras Escolhidas, Lisboa: edições 70, 2015, vol. IV, p. 125. Tradução: Lumir Nahodil.

- Sobre a legitimação pelos direitos humanos, in: Teoria Política. Obras Escolhidas, Lisboa: edições 70, 2015, vol. IV, p. 227 - 74.

LAMORE, Ch. Die Wurzeln radikaler Demokratie. Deutsche Zeitschift für Philosophie 41 (1993). 
LADEUR, K. H. "Subjektive Rechte und Theorie der Prozeduralisierung: von Universalismus des Rechts zur rechtlichen Modelbildung unter Ungewissheitsbedingungen" in: Kritische Justiz, vol. 40, n.1.

MANIN, B. On legitimacy and political deliberation, Political Theory, 15,1987.

MAUS, I. Freiheitsrechte und Volkssouveranität. Zu Jürgen Habermas' Rekonstruktion des Systems der Rechte. Rechtstheorie 26 (1995). 507-562.

MOREIRA, Luís. Fundamentação do direito em Habermas. Belo Horizonte: Ed. Mandamentos, 1999.

NOBRE, Marcos.; TERRA, Ricardo. (org.). Direito e democracia. Um guia de leitura de Habermas. São Paulo: Malheiros, 2008.

OLIVEIRA, M. Araújo. O Projeto Democrático de Sociedade e os Direitos Humanos. In: Ética, Direito e Democracia. São Paulo: Paulus, 2012.

PINZANI, Alessandro. Diskurs und Menschenrechte. Habermas' Theorie der Rechte im Vergleich. Hamburg: Kovac, 2000.

. Apresentação à edição brasileira. In: HABERMAS, J. Sobre a Constituição da Europa. São Paulo: Ed. Unesp, 2012.

. Habermas. P. Alegre: Artmed, 2009. 